\title{
Measuring what we manage - the importance of hydrological data to water resources management
}

\author{
BRUCE STEWART \\ Former Director, Climate and Water Department, World Meteorological Organization, CP 2300, CH-1211 Geneva, \\ Switzerland
}

\begin{abstract}
Water resources cannot be managed, unless we know where they are, in what quantity and quality, and how variable they are likely to be in the foreseeable future. Data from hydrological networks are used by public and private sectors for a variety of different applications. This paper discusses the value proposition behind the collection, analysis and use of hydrological data in support of these applications. The need for hydrological data and the requirements for the data are outlined, and information is provided on topics such as status of networks and data access and sharing. This paper outlines elements of the contribution by the World Meteorological Organization (WMO) to hydrological data collection and covers aspects related to quality management in the collection of hydrological data, especially regarding streamflow gauging, network design and capacity building for services delivery. It should be noted that the applications which make use of hydrological data may also be significantly impacted by climate change.
\end{abstract}

\section{INTRODUCTION}

One of the essential elements of life on this planet is freshwater. Sustainable development therefore demands sustainable management of the world's limited freshwater resources. The Integrated Water Resources Management (IWRM) approach is a more holistic approach to water management aimed at the efficient, equitable and sustainable development and management of the world's limited water resources and for coping with conflicting demands.

In implementing IWRM, water resources management institutions and professionals deal with a highly variable environment, in terms of, inter alia, weather, climate, land use and natural vegetation. They must be aware of and manage the response of a particular water regime to climatic and human interventions on hydrological regimes and water courses, including land-use changes, changes in water-use patterns, as well as the construction and management of dams and embankments, and changes in the freshwater-ocean interfaces, amongst others. Water managers have developed a range of standard methods to assess and manage water-related risks. Functioning water observation networks, producing fit-for-purpose data and information, and sharing of the data and information with all stakeholders are therefore essential for informed decision-making for water management and minimizing uncertainties (WMO 2009).

\section{NEED FOR WATER RESOURCES INFORMATION}

However, water resources cannot be properly managed unless we know where they are, in what quantity and quality, and how variable they are likely to be in the foreseeable future. Data from hydrological networks are used by public and private sectors for a variety of applications, including, inter alia, planning, designing, operating and maintaining multipurpose water management systems; the preparation and distribution of flood forecasts and warnings aimed at protecting lives and property; the design of spillways, highways, bridges and culverts; flood plain mapping; determining and monitoring environmental or ecological flows; managing water rights and transboundary water issues; education and research; protecting water quality and regulating pollutant discharges (USGS 2006).

The data quality required for a specific purpose will depend to a significant degree on the requirements of the above application areas and it needs to be recognized that not all data is fit-forpurpose in all application areas. For example, where there is a safety of life issue, greater confidence is required in the quality and accuracy of the data. 


\section{REQUIREMENTS FOR SOME PURPOSES}

\section{Storage yield}

Although there are no formal guidelines for the minimum period of record, reasonable stability with respect to yield analyses is generally reached with a record length of 10 to 20 times the critical period. Where little variability in streamflow occurs and where the need is mainly for seasonal storage (less than one year), a minimum record period of 10 to 20 years may be acceptable. However, in semi-arid to arid areas, over-year storage is generally required as critical periods of 5 to 10 years and longer are common. A record length of 50 to 100 years should preferably be used in such cases. Even where reasonably long streamflow records exist, worse floods and worse droughts than those historically observed are bound to occur in future. It is also virtually certain that the exact configuration of a streamflow sequence, as recorded in the past, will never be exactly repeated in future. However, it is evident that the longer the period of record on which the inflow sequence is based, the more reliable the estimation of the yield is likely to be (WMO 2009).

\section{Design rainfalls}

Sevruk and Geiger (1981) argue that for extreme precipitation frequency analysis a 25 -year period of record may be sufficient in humid regions such as the northern Russian Federation, but even a 50 -year period is not adequate in other regions where a distinct periodic fluctuation of precipitation exists. According to these authors, a record of 40 to 50 years is, in general, satisfactory for extreme precipitation frequency analysis. Yue et al. (2002) and Yue and Pilon (2004) show, as well, how statistical characteristics of the sample and record length can impact upon the power of common statistical tests (WMO 2009).

\section{Benefit-cost ratios}

There have been many studies in the past that have shown the high benefit-cost ratios associated with the use of hydrological data and this paper will not go further into that topic. Suffice to say that the value of hydrological time series records increases over time. For example, streamgauges with a long period of record are particularly valuable as they form a baseline for information about future changes. It is also important that, in the future, both the number of users and the ways in which the data are being used will increase, and the information's value will increase accordingly (USGS 2006).

\section{CURRENT STATUS OF NETWORKS}

Despite the above, there is growing evidence that hydrological networks are in decline. It is recognized that the cost of maintaining hydrological observation systems is growing and that the promise of next technologies that would provide quality data at reduced costs has not been realized at this time. There is a need for the hydrological community, together with the hydrological instrumentation industry, to look for improvements in monitoring systems that will enable the collection of quality data through systems that are more easily managed and maintained. National governments must also recognize that the collection of data of the required quality and accuracy does cost, but the costs are far outweighed by the ensuing benefits, especially in a changing and highly variable world.

\section{THE VALUE PROPOSITION - MAKING HYDROLOGICAL DATA COUNT}

The above said, it is essential that data be collected for the information (services and products) that can be derived from them and not just for the sake of data collection. Data must be raised up the data value information chain such that the true benefits of the data can be realized. This is accompanied by wide-spread recognition that data in themselves only become of value when they are used to produce services and products that can be used for decisions in support of socio- 
economic and environmental benefits. Indeed free and unrestricted access to data can and does facilitate innovation and the discovery of new ways to use, and purposes for, the data.

As indicated above, there are two aspects to making hydrological data count. First, we must collect data to meet the specific requirements of its intended purposes - fit-for-purpose data collected within a quality management framework. Secondly, we must have the practices and procedures in place to share these data for the benefit of the public good.

\section{Quality management framework - importance of standards in NHS operations}

As is noted in the Guide to Hydrological Practices (WMO 2009), defined standard procedures are an essential basis for ensuring the quality of a National Hydrological Service's (NHS) products and services. Increasingly, co-operators and clients require knowledge of the standards used by the Service as well as some indication of how well the Service is achieving those standards.

Reliable hydrological data and information are key inputs to the sound and wise management of water resources. Particularly under the changing paradigm of Integrated Water Resources Management, where decisions are increasingly being made through a consensual approach including relevant stakeholders, it is imperative that reliable data and information be accessible in a timely manner to facilitate informed decision making. The value of such data and information increases when they are provided through organization(s) that value and adhere to quality management principles.

Decisions in various sectors of the economy are becoming increasingly dependent on hydrological information. Depending on a particular country's circumstances it is possible that various agencies may be involved in hydrological data collection within a basin. Lack of standard procedures of obtaining measurements, storage of data, data manipulations, and protocols for data and metadata exchange, as well as acceptable analytical methodologies for transferring data into information, may often result in the generation of conflicting information, data and products being made available among various sectors, administrative regions, and diverse users. Such a situation can lead to disagreements, generate reluctance to cooperate and can undermine the importance and credibility of the work of the NHS. In transboundary basins, the equation evolves into another level of complexity requiring assurance and compatibility of the quality of data and products.

Given the uncertainties associated with hydrological processes and the impossibility to eliminate them in the data and information production, it is useful to make the clients aware of these uncertainties. Further, research on the Global Water Cycle and impacts of increasing climate variability and potential climate change on the availability of water resources requires the sharing and use of data from many countries. It is important that in such analyses the data be compatible, comparable and of known assured quality.

Although the costs of implementing and utilizing standard procedures are commonly perceived to be high, the cost of having no standards may well be higher. A Service may discover that observations it had made over several years were in error because of an unrecognized fault in an instrument, or that a flow record required complete reprocessing because a weir was incorrectly rated. Fixing such problems will invariably force the Service to incur more direct costs than it would have done had standard procedures been implemented and utilized. No less important, however, are the potential indirect costs of being perceived by the user community as a Service that does not always provide reliable data or services.

A core aspect of quality management is the delivery of products and services that are as close as possible to the users' requirements (specifications). This necessarily involves a continuous search for non-conformance in product and service specification, and the tracking of sources of such non-conformance. It implies considerable control of operational processes at all supervisory levels to ensure that instruments are regularly and properly calibrated and maintained, that field procedures are carefully selected and followed, that data are properly recorded and quality assured, and that improved methods of reporting data and information are evaluated and utilized. The more comprehensive the system of quality management, and the more understood it is among all employees, the more successful it will be in detecting errors, managing their correction, and 
avoiding their recurrence. Moreover, it will significantly enhance the confidence that clients and co-operators have in the quality of the NHS's products and services.

It is becoming increasingly obvious that we need to have a major shift in the construct and operations of hydrological data observation systems, but that this shift must take place in an environment of agreed standards, practices and procedures to ensure the fit-for-purpose nature of the data. There have been limited advances in hydrological monitoring practices and procedures in recent years and the costs of sustaining the existing infrastructure is not viable in many countries. But the benefits of the data are significant. Investigation and research into alternative observation and monitoring systems need to be encouraged and supported.

\section{Data access and data sharing}

When the 12th World Meteorological Congress (Cg-XII) adopted Resolution 40 in 1995, there was widespread agreement that the exchange of meteorological data at the global level was absolutely essential for there to be improvements in weather forecasting through data assimilation and ingestion into Numerical Weather Prediction models, and all WMO Members have benefited from this decision through enriched accuracy of forecasts and improved forecast lead times. This amply shows the value of global exchange of data.

Similarly, Resolution 25, adopted by Cg-XIII in 1999, assisted the exchange of hydrological data between countries, especially in shared (transboundary) river basins. Such data exchange greatly enhances the shared and sustainable management of water resources, and in times of flood threat, improves the capability of nations to provide much required flood forecasting and warning services. This shows the benefits of neighbour-to-neighbour exchange of data.

Now in the 21 st century, climate change has been shown to be a reality and we are again faced with coming to agreement with respect to the international exchange of data of importance at both global and regional levels. Changes in climate variability are important to many sectors and in a range of spatial and temporal dimensions. This is accompanied by widespread recognition that data in themselves only become of value when they are used to produce services and products that can be used for decisions in support of socio-economic and environmental benefits. Indeed free and unrestricted access to data can and does facilitate innovation and the discovery of new ways to use, and purposes for, the data. Figure 1 reminds us of this data value chain.

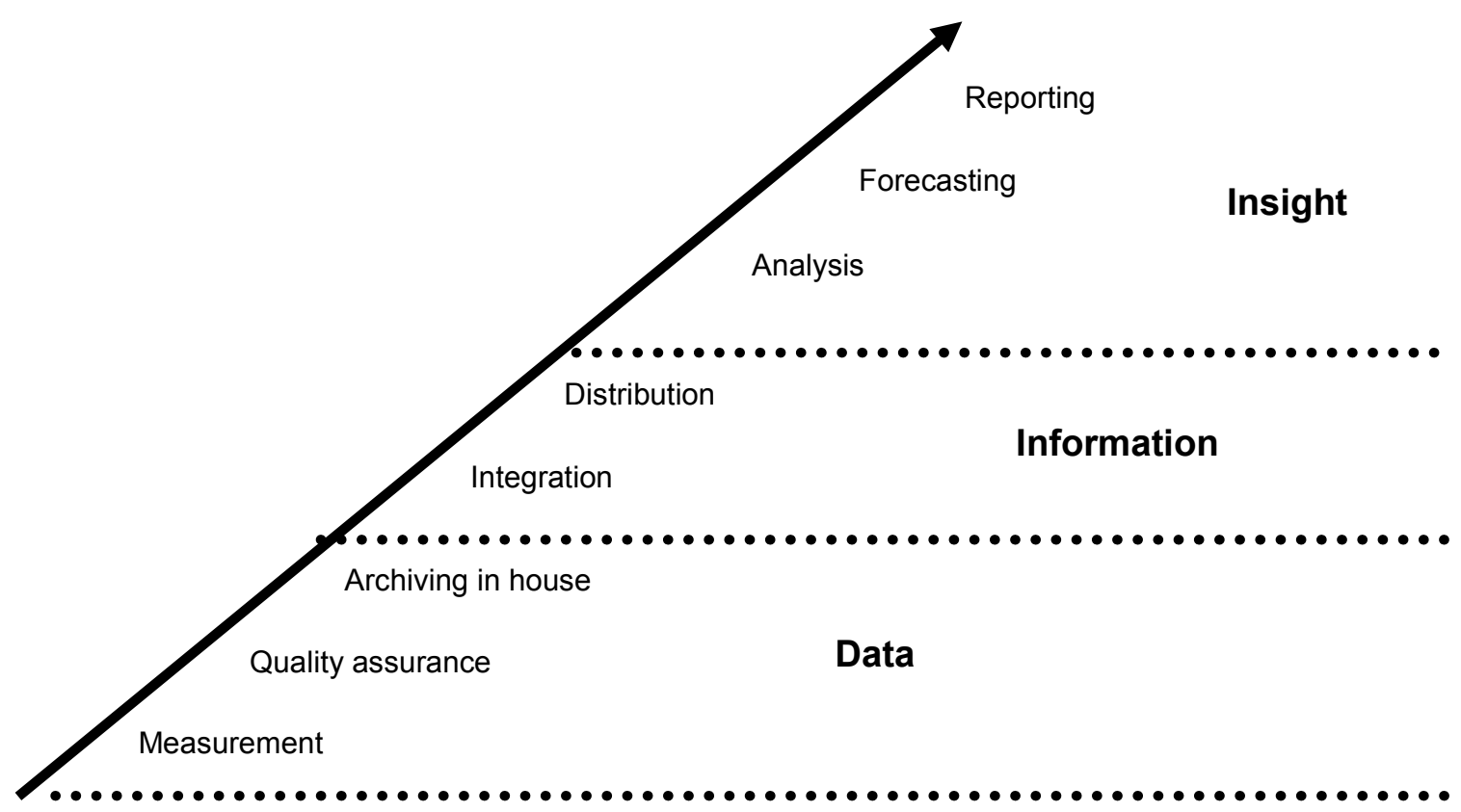

Fig. 1 Increasing value: Data $\gg>>$ Information $>>>$ Insight. 
Also, the 21st century has seen the rise of catch phrases such as: "you cannot manage what you haven't measured" and "data only reach their true value once they are used". For this to happen they must be available and accessible. Some benefits from free and unrestricted access to data include, inter alia:

1. better quality and greater variety of hydrological products and services, especially on a global and regional basis;

2. improvements to the numerous other services that are predicated on hydrological data and information;

3. enhanced national and international research into hydrological systems and an understanding of the hydrological system, leading to improved decision-making to benefit society;

4. better understanding/appreciation of the importance of hydrological data, and will likely lead to more support for the observing systems;

5. developing good regional hydrological products with the same quality and accuracy over the region;

6. promoting education of hydrology, leading to a better understanding of our environment, including its systems and changes;

7. promoting and strengthening collaboration between providers and users of hydrological data and products.

\section{WORLD HYDROLOGICAL CYCLE OBSERVING SYSTEM (WHYCOS)}

The World Meteorological Organization (WMO) launched the World Hydrological Cycle Observing System (WHYCOS) in 1993 to help overcome obstacles that hinder the achievement of sustainable development. WHYCOS, an umbrella programme of WMO, is a combined effort of participating countries, regional and basin institutions, international agencies and donors. WHYCOS provides a unique opportunity and tool for the protection, use and management of water resources in a sustainable manner.

WHYCOS is a global concept, and it is comprised of a number of individual, separate, regional Hydrological Cycle Observing System (HYCOS) initiatives. At the local level within a country, HYCOS brings together various agencies to work on delivering enhanced data and information products, such as the production and delivery of flood forecasts and warnings. An important complementary activity is the building of closer ties to communities and groups that have a primary mandate that benefits from access to the enhanced data, products and services, thereby achieving increased positive societal impacts. This results, in part, by increasing the capacities of institutions and by having communities working more closely together (WMO 2015).

\section{GLOBAL RUNOFF DATA CENTRE (GRDC)}

The GRDC is an international archive of data up to 200 years old, and fosters multinational and global long-term hydrological studies. Originally established two decades ago, the aim of the GRDC is to help earth scientists analyse global climate trends and assess environmental impacts and risks. Positioned as a facilitator for exchanges between data providers and data users, the GRDC has become a focal point for international cooperation. Researchers, universities and other organisations make use of the facilities available for research programmes and projects.

The Global Runoff Database at GRDC is a unique collection of river discharge data collected at daily or monthly intervals from more than 9000 stations in 160 countries. This adds up to around 370000 station-years with an average record length of 41 years. The GRDC provides discharge data and data products for non-commercial applications.

The GRDC operates under the auspices of the World Meteorological Organization (WMO) and supports research on climate variability and global change. The German Federal Institute of Hydrology (Bundesanstalt für Gewässerkunde or BfG) hosts the GRDC in Koblenz, Germany. 


\section{CONCLUSIONS AND RECOMMENDATIONS}

Climate change will impact on water resources availability in the future, and information and knowledge about freshwater can only become increasingly valuable. However, we must ensure that hydrological data are collected as efficiently and effectively as possible, meet user requirements, are targeted at enabling the sustainable management of our freshwater resources, and inform us about the impacts of our decisions.

We need to improve the manner in which we collect hydrological information and also how we present and make it available and accessible, and this will require an investment in new technologies and the requirement for them to be developed and implemented within a quality management framework.

Further, we have to promote and facilitate the free and open exchange of hydrological data, services and products in support of public good activities and initiatives. Our future is in our hands and we must make the hydrological data we collect count.

\section{REFERENCES}

Sevruk, B. and Geiger, H. (1981) Selection of distribution types for extremes of precipitation. Geneva: World Meteorological Organization.

United States Geological Survey (USGS) (2006) Benefits of the USGS Stream Gauging Program - Users and uses of US streamflow data. http://water.usgs.gov/osw/pubs/nhwc_report.pdf

World Meteorological Organization (2009) Guide to Hydrological Practices Volume II, Management of Water Resources and Application of Hydrological Practices. WMO-No. 168, Sixth edition 2009.

World Meteorological Organization (2015) Hydrological information systems for integrated water resources management. WHYCOS Guidelines. For development, implementation and governance. Under publication.

Yue, S., Pilon, P. and Cavadias, G. (2002) Power of the Mann-Kendall and Spearman's rho tests for detecting monotonic trends in hydrological series. Journal of Hydrology 259, 254-271.

Yue, S. and Pilon, P. (2004) A comparison of the power of the t test, Mann-Kendall and bootstrap tests for trend detection. Hydrological Sciences Journal 49(1), 21-37. 